\title{
Submucosal tunnelling endoscopic resection: first successful experience from Sri Lanka and a review of the literature
}

\author{
B. P. N Wijerathne, C. N Wijesurendere, T. Wijerathne \\ University Surgical Unit, Colombo South Teaching Hospital, Kalubowila, Sri Lanka
}

Key words: Submucosal tunneling endoscopic resection; lipoma of oesophagus

\section{Introduction}

Submucosal Tunnelling Endoscopic procedures are novel popular techniques for successful treatment of upper gastrointestinal conditions such as Achalasia of cardia and mural lesions of the oesophagus.

\section{Presentation}

A sixty four year old farmer presented with a history of dysphagia and regurgitation for eight months. He had a poor response to medical management of reflux and had grade- 2 dysphagia at presentation. During upper gastrointestinal endoscopy, we found two submucosal lesions protruding to the lumen at $27 \mathrm{~cm}$ and $38 \mathrm{~cm}$ and a type- 1 hiatus hernia.

Contrast enhanced computerized tomography (CECT) showed two adjacent well circumscribed submucosal masses measuring $2.2 \mathrm{~cm}$ and $2.5 \mathrm{~cm}$ with calcifications within. There were no features to suggest infiltration. It was compatible with two submucosal lipomas of the oesophagus. A decision was made to perform STERT procedure.

Under general anaesthesia, the patient was positioned supine. The procedure was performed by a surgeon experienced in therapeutic upper gastrointestinal endoscopy. Initially, gastroscopy was performed to assess the position of the lesion for accurate planning. Methylene blue was used to inject into the submucosa to facilitate submucosal dissection. A vertical incision with diathermy was made approximately $5 \mathrm{~cm}$ above the proximal lesion. The tip of the endoscope was negotiated into the submucosal space and carbon dioxide was inflated.

Dissection of the submucosal space was carried out with a hybrid knife which combines a water jet and monopolar diathermy. Both lesions were carefully dissected out, grasped with a snare and removed separately. Haemostasis was confirmed and the mucosal entry site was closed with

\footnotetext{
Correspondence: Chinthaka Wijesurendere

E-mail: cnwijesurendere@gmail.com

Received: 10-08-2018 Accepted: 03-11-2018

(iD http://orcid.org/0000-0002-0631-2449

DOI: http://doi.org/10.4038/sljs.v36i4.8556
}

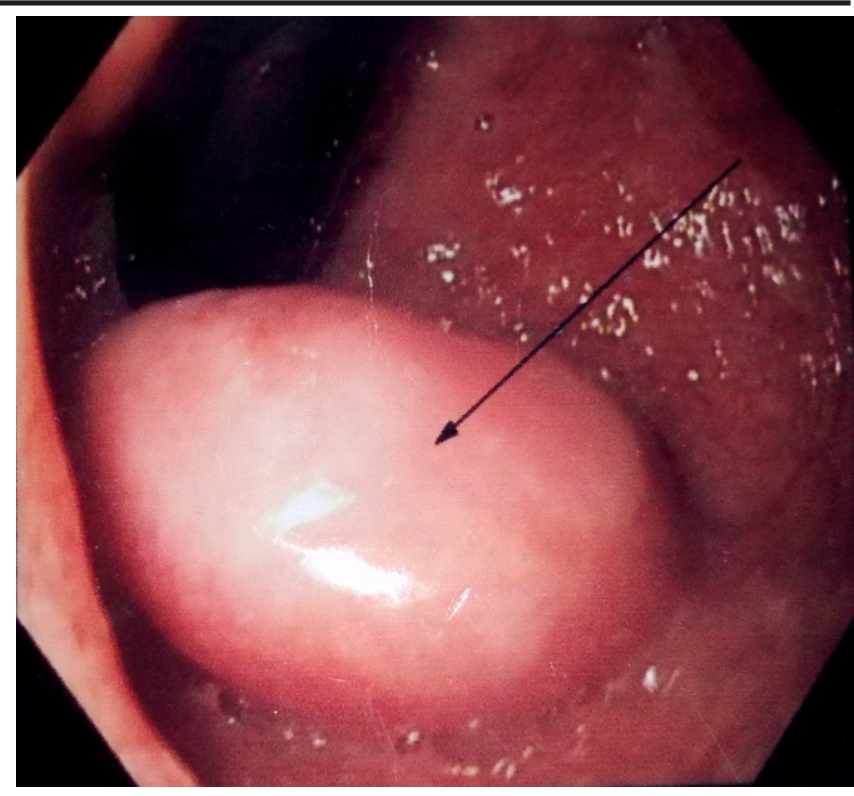

Figure 1. Endoscopic view of the submucosal mass (arrow) in the lower oesophagus

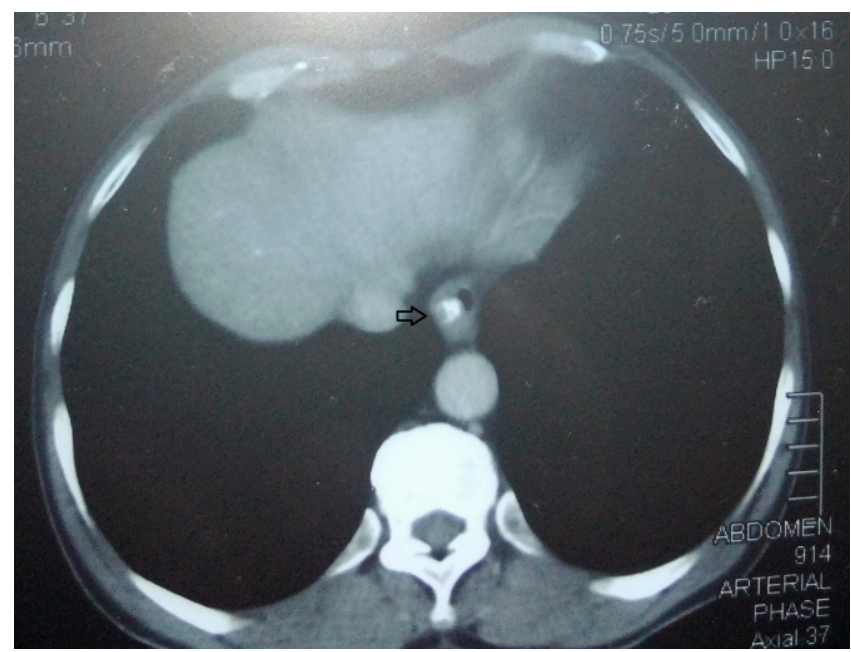

Figure 2. The CECT showing the calcified mass (arrow) at lower oesophagus

endoscopic clips. The operative time was ninety minutes. The patient was kept nil by mouth for 24 hours and oral intake was established gradually. He was discharged on the third day. The histology of both lesions confirmed that they were lipomas. The patient made a good recovery and dysphagia was completely improved after the procedure. 


\section{Discussion}

Endoscopic submucosal dissection (ESD) is now becoming widely used for removal of benign and early malignant tumours of the gastrointestinal tract namely the oesophagus, stomach, colon and rectum. This method was first conceptually introduced to the world by Japanese gastroenterologists approximately 30 years ago and it is practised widely in East Asia [1,2]. Its main advantage over other endoscopic resection techniques such as endoscopic mucosal resection (EMR) is the ability to obtain en-bloc removal of lesions. This has enabled a superior histological assessment and a better treatment outcome [3]. To date, there are no reports on STERT/EMR procedures from Sri Lanka.

While there are numerous (Japanese, European and American etc.) guidelines available on lesion selection in cancer, there is no published guide on a selection of benign lesions of the oesophagus for ESD. While $2 \mathrm{~cm}$ is the cut-off diameter for malignant lesions considered for ESD, there is no cut-off size for benign lesions for STERT procedure of oesophagus [4].

When it comes to patient selection, endosonography is an adjunct other than endoscopic assessment and CECT which was not used in our case.

Technology is constantly being evolved. High definition therapeutic endoscopy with a single instrument channel being the basic prerequisite, scopes with higher magnification with optical zoom, dual instrument channels and enhanced flexibility are some of the new developments that are currently available [5]. Gas insufflations with carbon dioxide has been proven to be superior to standard air in producing lower rates of mediastinal emphysema and post procedure discomfort in a randomized study [6].

STERT is essentially natural orifice transluminal endoscopic surgery. Hence, its key advantage to the patient is a scar-less operation. It also eliminates most complications related to conventional surgery for such conditions (laparoscopic or open) such as post-op pain, wound complications, hernia, thromboembolism etc.

STERT/ESD is technically demanding when compared to endoscopic mucosal resection (EMR) with a higher rate of complications such as bleeding, perforation and stricture formation. In a review by Isomoto et al, a pooled perforation rate in a large series of oesophageal ESD was $2.3 \%$ [7].

In Sri Lanka, we're still at a preliminary stage with ESD/STERT and the avenues of ESD are yet to be explored. Strategies could be developed for identification of cancers at an earlier stage for use of this method and establishment of a few high-volume centres for advanced therapeutic endoscopy such as ESD/STERT is a necessity in Sri Lanka.
All authors disclose no conflict of interest. The study was conducted in accordance with the ethical standards of the relevant institutional or national ethics committee and the Helsinki Declaration of 1975, as revised in 2000 .

\section{References}

1. Hirao M, Masuda K, Asanuma T, Naka H, Noda K, Matsuura K, et al. Endoscopic resection of early gastric cancer and other tumors with local injection of hypertonic saline-epinephrine. Gastrointest Endosc [Internet] ;34(3):264-9. Available from: http://www.ncbi.nlm.nih.gov/pubmed/3391382

2. Ma MX, Bourke MJ. Endoscopic submucosal dissection in the West: current status and future directions. Dig Endosc [Internet]. 2017 Sep 7 ; Available from:

http://www.ncbi.nlm.nih.gov/pubmed/28884493 https://doi.org/10.1111/den.12960

3. Xu M-D, Cai M-Y, Zhou P-H, Qin X-Y, Zhong Y-S, Chen W-F, et al. Submucosal tunneling endoscopic resection: a new technique for treating upper GI submucosal tumors originating from the muscularis propria layer (with videos). Gastrointest Endosc [Internet]. 2012 Jan;75(1):195-9. Available from: http://www.ncbi.nlm.nih.gov/pubmed/22056087

https://doi.org/10.1016/j.gie.2011.08.018

4. Ono H, Yao K, Fujishiro M, Oda I, Nimura S, Yahagi N, et al. Guidelines for endoscopic submucosal dissection and endoscopic mucosal resection for early gastric cancer. Dig Endosc [Internet]. 2016 Jan;28(1):3-15. Available from: http://www.ncbi.nlm.nih.gov/pubmed/26234303 https://doi.org/10.1111/den.12518

5. Maple DO FASGE JT, Abu Dayyeh MPH BK, Chauhan FASGE SS, Ha Hwang FASGE J, Komanduri S, Manfredi M, et al. Endoscopic submucosal dissection. 2015 Available https://doi.org/10.1016/j.gie.2014.12.010

6. Maeda Y, Hirasawa D, Fujita N, Ohira T, Harada Y, Yamagata T, et al. Carbon dioxide insufflation in esophageal endoscopic submucosal dissection reduces mediastinal emphysema: A randomized, double-blind, controlled trial. World J Gastroenterol [Internet]. 2016 Aug 28;22(32):7373-82.

Available from:

http://www.ncbi.nlm.nih.gov/pubmed/27621583 https://doi.org/10.3748/wjg.v22.i32.7373

7. Isomoto H, Yamaguchi N, Minami H, Nakao K. Management of complications associated with endoscopic submucosal dissection/ endoscopic mucosal resection for esophageal cancer. Dig Endosc [Internet]. 2013 Mar;25:29-38. Available from: http://www.ncbi.nlm.nih.gov/pubmed/23368404 https://doi.org/10.1111/j.1443-1661.2012.01388.x 